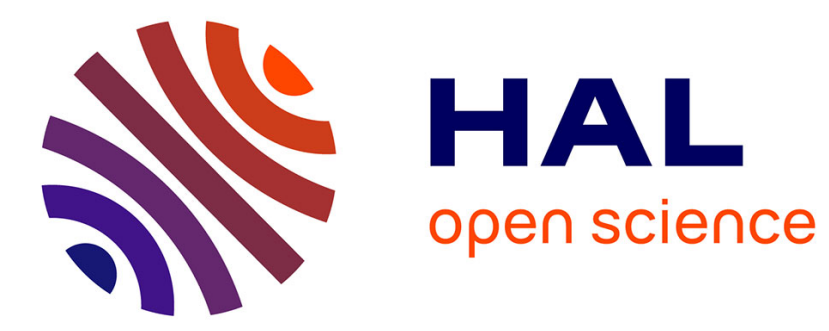

\title{
Comparing tactile maps and haptic digital representations of a maritime environment
}

Mathieu Simonnet, Stéphane Vieilledent, Jacques Tisseau, Dan Jacobson

\section{To cite this version:}

Mathieu Simonnet, Stéphane Vieilledent, Jacques Tisseau, Dan Jacobson. Comparing tactile maps and haptic digital representations of a maritime environment. Journal of Visual Impairment and Blindness, 2011, 105 (4), pp.222-234. hal-00732482

\section{HAL Id: hal-00732482 \\ https://hal.science/hal-00732482}

Submitted on 17 Sep 2012

HAL is a multi-disciplinary open access archive for the deposit and dissemination of scientific research documents, whether they are published or not. The documents may come from teaching and research institutions in France or abroad, or from public or private research centers.
L'archive ouverte pluridisciplinaire HAL, est destinée au dépôt et à la diffusion de documents scientifiques de niveau recherche, publiés ou non, émanant des établissements d'enseignement et de recherche français ou étrangers, des laboratoires publics ou privés. 


\title{
Comparing tactile maps and haptic digital representations of a maritime environment
}

\author{
Mathieu Simonnet \\ Institut de Recherche de l'Ecole Navale (EA 3634) (IRENAV) Ecole Navale- Arts et Métiers ParisTech \\ Stéphane Vieilledent, Jacques Tisseau, Dan Jacobson \\ Laboratoire d'Informatique des Systèmes Complexes (LISYC), Ecole Nationale d'Ingénieurs de Brest - \\ Université de Bretagne Occidentale - Brest : EA3883 - ENSTA Bretagne - Institut Supérieur des Sciences et \\ Technologies de Brest (ISSTB), Centre Européen de Réalité Virtuelle (CERV) ENIB
}

\begin{abstract}
A map exploration and representation exercise was conducted with totally blind participants. Representations of maritime environments were presented either with a tactile map or with a digital haptic virtual map. We assessed the knowledge of spatial configurations using a triangulation technique. Results revealed that both types of maps are equivalent.

\section{Problem Statement}

All over the world, blind people practice sailing. However, they do not have access to a nonvisual equivalent to maritime geographic information system (GIS) that provide digital charts, updated positioning, and real time weather updates, as commonly used by sighted sailors. This study aims at building upon previous technological and psychological knowledge to assess haptic (tactile-kinesthetic) and auditory virtual maritime maps from SeaTouch, a maritime GIS for blind sailors. Thus, we compared spatial performances obtained after the exploration of regular maritime maps in relief (tactile maps) and novel virtual maps from SeaTouch.

This research is the first step of the SeaTouch Project which expects to provide blind sailors with a haptic and auditory GIS to provide them with a more functional and complete sailing and navigation information.
\end{abstract}

\section{Introduction}

Since Leonard \& Newman (1967) showed that vision is neither necessary nor sufficient for spatial coding, many studies have revealed the capabilities of blind people to solve spatial problems (see Ungar, 2000 for a review). However Kitchin et al. (1997) emphasized that a deficit in perceptive experience could decrease spatial performances. More precisely, Millar (1988) pointed out that less experience of environmental perceptions lead blind people to essentially encode the positions of objects in reference to their own body rather than relative to each other (Spencer and Blades, 1986). This disctinction corresponds to the two main spatial reference frames which are broadly defined in spatial cognition. In an egocentric 
reference frame, the mental representations of locations in memory are computed with respect to the particular position and perspective of the individual. Conversely, an allocentric reference frame allows to locate points within a framework external to the holder of the representation and independent of his or her position (Klatzky, 1998). Whatever the sensory modalities implicated, sighted and blind people can perceive their environment and perform actions in an egocentric frame of reference. However, to complete a holistic, more gestalt overview of space, learning space requires an individual to abstract spatial representations into an allocentric frame of reference (Thinus-Blanc, 1996). In other words, mastering navigation consists in coordinating the forward field of perception and the corresponding allocentric mental map (Wickens, 1999). Piaget \& Inhelder (1967) showed that this process relies on the construction of spatial invariants, considered as a set of common points between egocentric and allocentric to facilitate the coordination and organization of these reference frames (Thinus-Blanc, 1996). Siegel \& White (1975), suggested landmarks, as unique noteworthy elements of environment, are able to provide these invariants when they can be identified in the field of perception (egocentric) as well as in the constructed, map like representation (allocentric). There is continual debate about the nature of information used to develop spatial cognition, for example (qualitative vs quantitative), and also about the role and relationships between routes and landmarks. A coherent, survey knowledge of space, a mental construct of the environment is known as a cognitive map, as first described by (Tolman, 1948). So, the more landmarks we perceive and connect, the more reliability, utility and accuracy of our cognitive map may have. Thus, because of the features of tactile and auditory modalities, blind people may have to integrate sequential information to generate an overall mental representation.

Geographical charts, maps and spatial displays are powerful tools to build spatial knowledge (Kosslyn et al. 1974). The power of tactile maps (i.e. geopraphical maps in relief) make perceptible what is not for blind people (Golledge, 1991, 1993, Ungar et al., 1996 and Hatwell et al., 2003). Tactile maps were used by Espinosa et al. (1998) in a set of experiments to verify if blind people could take advantage of tactile maps to learn the spatial layout of an urban environments. Results showed that the combination of direct environmental experience and the tactile map was more efficient than the direct experience alone or combined with verbal description, confirming the results previously articulated by Ungar et al. (1994). The latter designed experiments with blind participants and asked them to estimate directions between landmarks after having experienced the layout either directly, by walking around it, 
or indirectly by examining a tactile map. The main findings of this research were that the use of tactile maps increases blind peoples' spatial knowledge.

Tatham (2003) suggested that a better understanding of perceptual and cognitive processes, involved in spatial information processing combined with new technological possibilities provide an opportunity for delivering more responsive and salient information for individuals who are blind. Different types of digital maps have been adapted for blind people (Jansson, 1999, Nemec et al., 2004, Rice et al., 2005, Lahav \& Mioduser, 2008). It is necessary to investigate how to effectively display digital and multimodal information (such as haptic and auditory information) are at provinding blind people with accessible digital maps. This involves assessing the efficiency and efficacy of these virtual maps. Jansson and Billberger (1999) used the Phantom Omni forced feedback device, a haptic interface that allows movements in six degrees of freedom. The participant holds the stylus with one hand and force-feedback is provided as tangible haptic information to this stylus via computer controlled electromagnetic motors. The authors compared accuracy in identifying virtual and real forms (spheres, cones...). Results revealed that virtual shapes are less accuratly recognized that real ones. Later, Nemec et al. (2004) performed an experience employing a force feedback joystick (Wingman Strikeforce $3 D$ from Logitech $^{\odot}$ ) originally intended to be used in computer games. Blind people explored a virtual environment and a tactile map of the same environment. Results show that precisions of scene topology described by the participants were equal in the two conditions. Lahav and Mioduser (2008) studied the exploration strategies that blind people used in an haptic and auditory virtual environment (VE). This multisensory VE was implemented to interface with the Microsoft ${ }^{\circledR}$ SideWinder Force Feedback Joystick. Using this system, blind participants could move within the VE and feel virtual objects. The experiment consisted in comparing spatial performances of two participant groups, one who explored a real classroom and the second who explored a virtual classroom. The results confirmed that virtual environment provided blind people with access to spatial knowledge. Furthermore, spatial performances obtained in VE revealed that blind people are able to encode space in an allocentric spatial frame of reference. However, it is highly likely that this result could be confounded by the difference between locomotion in large scale space and manipulation in small scale space.

One of the lingering questions is how do these virtual environments compare to information presented in a conventional tactile map?

Overview of this study: 
The present study has two goals. First we wanted to gain additional insight about the utility of exploring haptic auditory representations of a spatial scene, when compared to a tactile map for the consistency of spatial cognitive maps elaborated by blind people. Blind participants explored both the map in relief (tactile map) and the virtual environment rendering of the same maritime geographical configuration with key landmarks (beacons). In addition, our second goal was to determine if exploring such a virtual map can help to actively coordinate egocentric and allocentric spatial frames of reference in virtual environments in order to build more efficient spatial cognitive maps as analogy to wayfinding and navigation in a natural environment (e.g. an urban centre). An experimental protocol requiring the subjects to estimate directions between different objects of the environment was used. The use of aligned and misaligned situations provided a mechanism for investigating the role egocentric and allocentric spatial frames of reference. The role of their coordination in the development of a coherent spatial cognitive map was evaluated by the use of misaligned questions which demanded participants to associate both spatial frames of reference.

\section{Method}

\subsection{Participants}

Six blind adults participated in the study, one woman and five men. The mean age of the group was 38 (S.D 9) years old. All participants had no residual vision or light perception. Two participants were congenitally blind and the four others lost vision later in life (Table 1).

\begin{tabular}{|l|l|l|l|l|}
\hline & Gender & Current age & Age of blindness & Studies level \\
\hline Participant 1 & M & 27 & 24 & Baccalaureate \\
\hline Participant 2 & M & 27 & 18 & Baccalaureate \\
\hline Participant 3 & M & 45 & 23 & Master Grade \\
\hline Participant 4 & M & 47 & 42 & Baccalaureate \\
\hline Participant 5 & F & 44 & 0 & Baccalaureate \\
\hline Participant 6 & M & 36 & 0 & Baccalaureate \\
\hline
\end{tabular}

Table 1: Gender, current age, age of blindness and studies level of the participants.

The participants were recruited from a blind sailing association in Brest (France) which limited our available sample size to six individuals. All of the participants were familiar with maritime maps and used their own personal computers with text-to-speech software on a daily basis.

\subsection{Materials}

In this study, we used two maps, tactile and virtual. The tactile and virtual maps were $40 \mathrm{~cm}$ wide and $30 \mathrm{~cm}$ high. Both map scenes were the same. They were comprised of a 
homogeneous land mass ( $25 \%$ of the map area), the sea and six salient landmark objects within the ocean. In maritime terms these landmarks were referred to as beacons.

\subsubsection{Tactile map}

In the tactile map the sea was represented by smooth plastic, the land was indicated by a rough texture, generated through a mixture of sand and paint. The salient objects were six raised markers in different geometric shapes: Triangle, Circle, Diamond, Square, Trapezoid and an Hourglass shape. All of the map features had undergone prior testing for legibility and ease of discrimination.

\subsubsection{Virtual map}

The virtual map was generated by SeaTouch, a haptic and auditory JAVA application developed in the European Centre for Virtual Reality for the navigational training of blind sailors. The virtual map was equivalent to the tactile map except that the virtual map was rendered in the vertical plane providing the implicit assumption that the workspace was aligned north up. The rendering of the sea surface was soft and sounds of waves were played when the participant touched it. The rendering of the earth was rough and extruded by one centimeter from the surface of the sea. When the haptic curser came into contact with the land the sound of song of birds that are found inland were played. Between the land and the sea, the coastline was rendered as a vertical cliff that could be touched and followed. In this case, the sounds of sea birds were played. The salient objects, the six beacons, were generated by a spring effect, an attractor field analogous to a small magnet of 1 centimetre in diameter. When the haptic cursor contacted with them a synthetic voice announced the names of each object (Boat, Gull, Float, Penguin, Guillemot and Egret).

\subsubsection{Experimental Design}

To remove a potential learning effect during the exploration of the haptic and tactile maps, a cross-over experimental design was used. If participants were presented with exactly the same configuration of the landmarks on tactile and virtual maps, a learning effect could be formed in the second condition. As an example, after exploring the tactile map the participant would have formed a level of spatial knowledge that would confound the participants learning of thesame configuration in the virtual condition. In order to avoid any learning effect a rotation of sixty degrees was applied to the initial configuration .

\subsection{Procedure}

\subsubsection{Training phase}

To ensure that the participants mastered haptic and auditory interactions with the SeaTouch map, they trained with the system until they were able to "navigate" easily in the virtual 
environment. In other words we confirmed that they were able to follow the coastlines, move over the surface of the sea and locate beacons with the stylus of the haptic device.

Tactile map training did not occur as all of the participants had already worked extensively with such maps.

\subsubsection{Exploration}

Before beginning any movement, the blind participants were informed that the ultimate purpose of the exploration phase was to obtain enough spatial knowledge to be able to answer questions about pointing to beacons without reference to the tactile or virtual scenes.

Exploring the tactile map consisted of moving the own fingers over the surface of the map, exploring the virtual one consisted in displacing the stylus of the haptic device within the virtual environment. In both cases, the exploration stopped when the participant could remember the names of the six beacons and localize them on the map without confusion.

Participants were told that the goal of tactile and virtual maps explorations was to be able to estimate directions between the different beacons. So as not to favor any conditions, three participants first explored tactile map and the three others began with the virtual one.

\subsubsection{Data Collection}

After the exploration of each map, participants pointed from each of the six beacons to three others. They answered eighteen questions in an aligned situation and eighteen in a misaligned situation. Data was collected from participants provided using a tactile protractor that was fixed to the table in front of them.

In the aligned situation, a sample question follows: "You are at the Gull and facing the north, what is the direction of the Egret?" Here, the axes of the participant and the north were aligned. To estimate this direction, the participant can presumably work primarily from an egocentric frame of reference.

In the misaligned situation, a sample question follows: "You are at the Gull and facing the Penguin, what is the direction of the Egret?" Here, the axes of the participant and the north were different. So, the participant had to process a mental rotation to combine these two axes and estimate the required direction. In other words participants were forced to coordinate themselves by integrating egocentric and allocentric directions.

\subsection{Data analysis}

From the estimated directions, we computed triangulations. More precisely, within each series of 18 questions, each beacon was targeted three times from three others beacons. 
Consequently, we were able to implement the projective convergence technique (Hardwick et $a l .$, 1976). Three non parallel lines pointing to the same location were recorded setting out the three sides of an error triangle (Figure 1). The area of this error triangle (AET), expressed in $\mathrm{km}^{2}$ (at map scale), indicates the consistency of the responses (Kitchin \& Jacobson, 1997). A high level of consistency is obtained when AET is closer to $0 \mathrm{~km}^{2}$ whereas the consistency diminishes when AET increases.

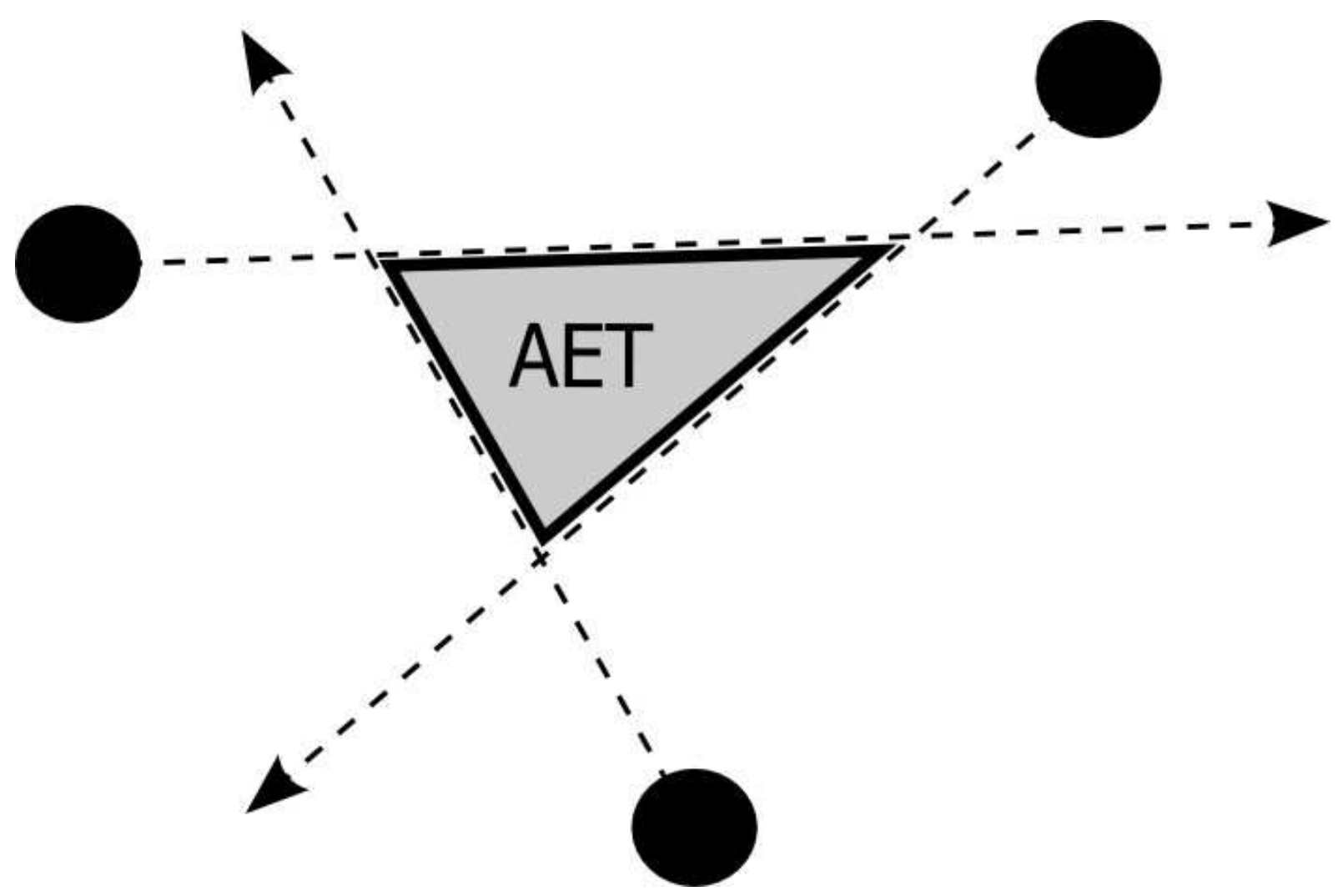

Figure 1: The projective convergence technique (Hardwick et al. 1976).

The three black points are the initial beacons from which the estimations are. The dashed lines are the estimated directions. For each beacon to be localized, the area of the error triangle (AET) could be drawn from the intersection points of these estimated directions.

We analyzed 6 (subjects) x 6 (beacons) x 2 (map conditions) x 3 (questions) x 2 (alignment situations) i.e. 432 responses allowing computation of 144 AET considered as the indicator of the consistency of the global spatial representation.

A preliminary inspection of the data revealed that AET did not follow a normal distribution (Lilliefors test, $\mathrm{p}>.05$ ). Thus, statistical paired comparisons were performed on both map conditions (tactile $v s$ virtual) in both alignment situations (aligned and misaligned) using the non parametric Wilcoxon test. 


\section{Results}

From a qualitative point of view, it appears that the error triangles generated for a typical participant are smaller in aligned situation (Figures 2A and 2B) than in misaligned situation (Figure 2C and 2D). Moreover, no error triangle goes beyond the boundaries of either the tactile or the virtual workspace in aligned situation whereas some error triangles extend beyond the workspaces in the misaligned situation. Triangles obtained after tactile exploration are smaller than virtual ones in aligned situation (Figures 2A and 2B). Contrary to this, tactile triangles are larger than virtual ones in misaligned situation (Figures 2C and 2D). In other words, triangles obtained after tactile exploration can be different in size according to the alignment situations (Figures 2A and 2C). Conversely, the size of the triangles obtained after virtual exploration remained relatively constant across the alignment situations (Figures $2 \mathrm{~B}$ and 2D). 

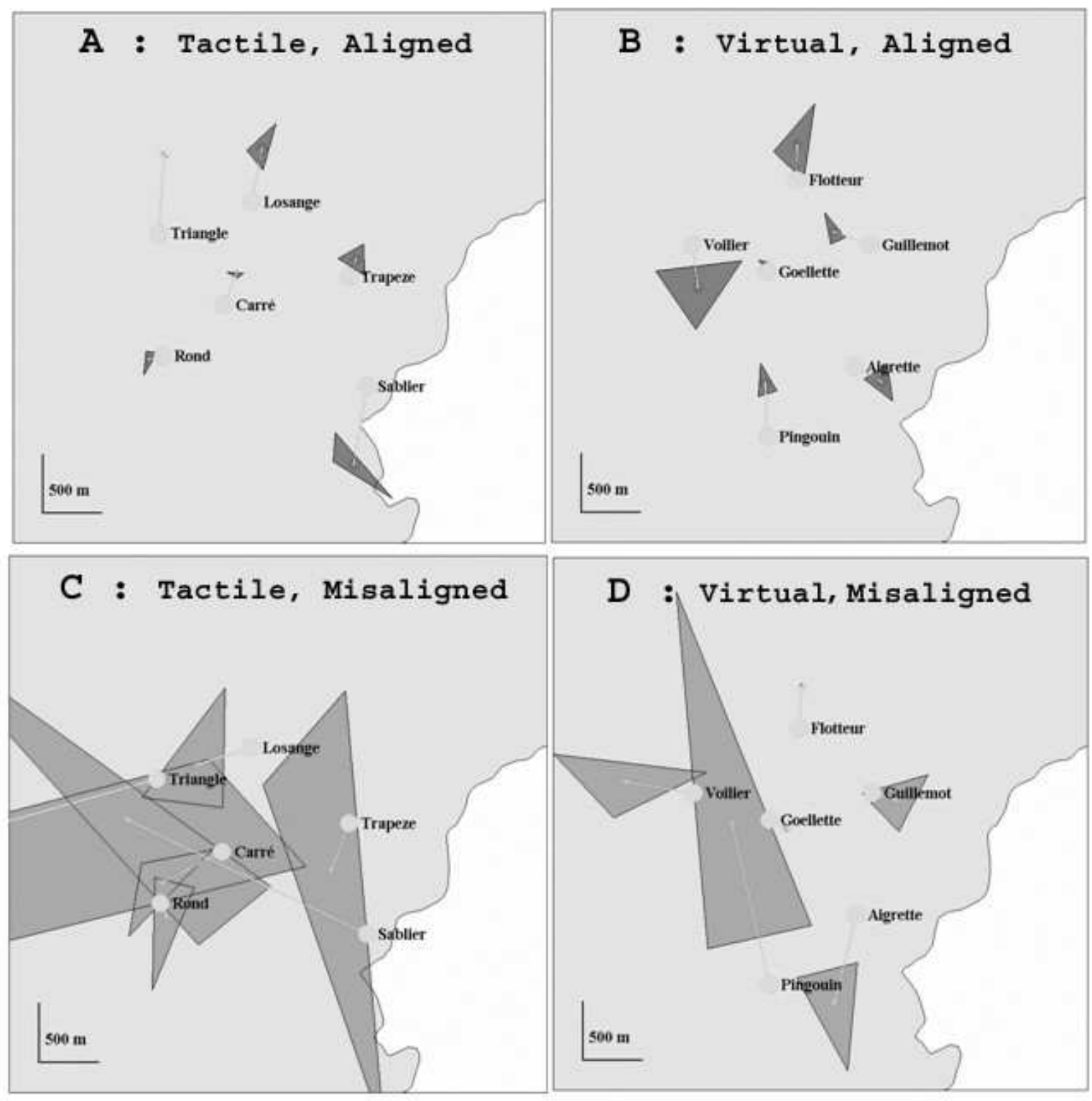

Figure 2: Error triangles obtained by a sample participant after tactile and virtual maps explorations. The pictures on the left correspond to the tactile condition while the picture on the right correspond to the virtual condition.

Pictures at the top depict error triangles in aligned situations and pictures at the bottom depict error triangles in misaligned situation.

\subsection{Alignment effect}

All the participants reported that they encountered more difficulties in answering the questions in the misaligned situation. They attributed this additional difficulty to the necessity to rotate their mental map and update their orientation prior to point with the protractor.

These difficulties can also be observed when analyzing the data quantitatively. Indeed, AET was equal to 0.65 (SD 1.76) $\mathrm{km}^{2}$ with values spread from $4 \mathrm{~km}^{2}$ to $12.14 \mathrm{~km}^{2}$ in aligned situation and equal to 1.70 (SD 2.68) $\mathrm{km}^{2}$ with values spread from $145 \mathrm{~km}^{2}$ to $13.63 \mathrm{~km}^{2}$ in 
misaligned situation. Half of the data were below $0.1 \mathrm{~km}^{2}$ in aligned situation and below 0.69 $\mathrm{km}^{2}$ in misaligned situation. These values indicate that not only the mean value almost trebled when the axes of the participant and the north were different but we also noticed specific data distributions in each situation (Figure 3). Although most of the data remained below $1 \mathrm{~km}^{2}$, less than $5 \%$ of them exceeded $4 \mathrm{~km}^{2}$ and $7 \mathrm{~km}^{2}$ in aligned and misaligned situation respectively. This result mainly originated from differences in frequencies obtained for high consistency levels as can be seen for AET lower than $3 \mathrm{~km}^{2}$. In the aligned situation, among the 62 AET values below $1 \mathrm{~km}^{2}, 32$ were obtained after tactile exploration whereas 30 were obtained after virtual exploration. For AET greater than $1 \mathrm{~km}^{2}$, the differences between tactile and virtual frequencies never exceeded 1. Conversely, in misaligned situation, among the 50 AET values below $1 \mathrm{~km}^{2}, 19$ were obtained after tactile exploration whereas 21 were obtained after virtual exploration and differences still remained for AET below $2 \mathrm{~km}^{2}$ with 10 responses in tactile condition and 4 in virtual condition. Nevertheless, such differences tended to disappear for AET greater $2 \mathrm{~km}^{2}$.

In addition, only $11 \%$ of the results were greater than the area of the polygon delimited by the six beacons itself $\left(2.44 \mathrm{~km}^{2}\right)$ in aligned situation versus $25 \%$ in misaligned situation denoting, once again, a lower consistency in this later case.

The comparison of AET the differences in the consistency of the estimated directions in aligned and misaligned situations were significant $(\mathrm{p}<.001)$, confirming the previous research by Rossano \& Warren (1989). 


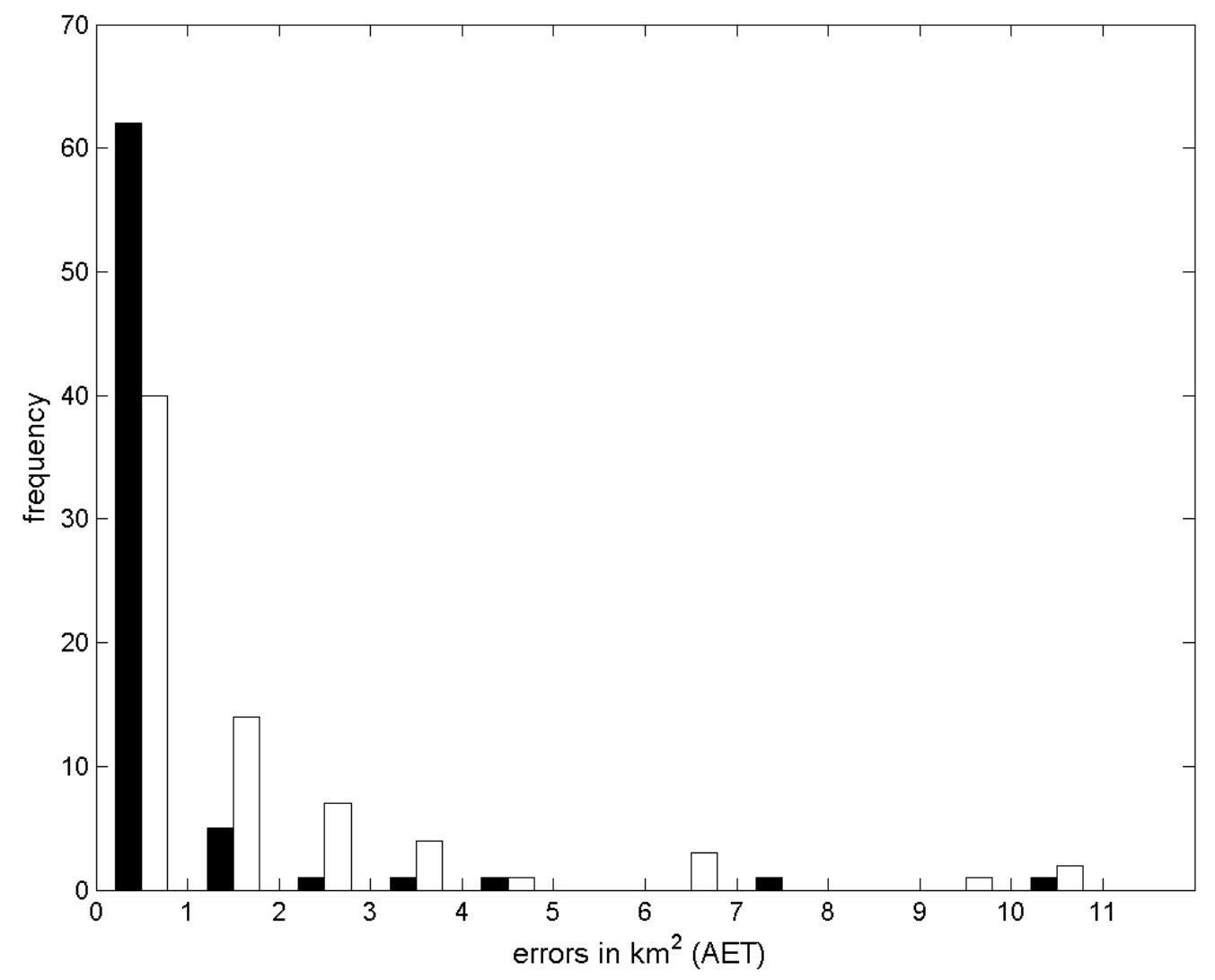

Figure 3. Frequencies of AET in aligned (Black bars) and misaligned (white bars) situations.

\subsection{Map effect}

There were time differences in exploration duration, the tactile map was 6'23" (SD 2'03'') and 10'17', (SD 6'12') for the virtual one. Participants reported greater difficulties in virtual condition than in tactile one. The results concerning AET were very similar in both conditions, AET was equal to 0.98 (SD 1.99) $\mathrm{km}^{2}$ with values spread from $0.359 \mathrm{~km}^{2}$ to 13.29 $\mathrm{km}^{2}$ in tactile condition and equal to 1.37 (SD 2.61) $\mathrm{km}^{2}$ with values spread from $4 \mathrm{~m}^{2}$ to $13.63 \mathrm{~km}^{2}$ in virtual condition. Half of the data were below $0.31 \mathrm{~km}^{2}$ in tactile condition and below $0.25 \mathrm{~km}^{2}$ in virtual condition. We discovered this similarity between the map conditions when analyzing the data distribution (Figure 4). There are no differences for values below $1 \mathrm{~km}^{2}$ and the differences remained minimal for the other clusters of the distribution. The majority of the data remained below $1 \mathrm{~km}^{2}$ with less than $5 \%$ of error triangles them exceeding $4 \mathrm{~km}^{2}$ and $7 \mathrm{~km}^{2}$ in tactile and virtual condition respectively. Of the 51 error triangle values lower than $1 \mathrm{~km}^{2}, 32$ were obtained in the aligned condition and 19 in misaligned situation for the tactile condition with a similar repartition for the virtual condition (30 and 21 in aligned and misaligned situation respectively). Finally, 11\% of the results were 
greater than the area of the polygon delimited by the six beacons itself $\left(2.44 \mathrm{~km}^{2}\right)$ in tactile condition versus $18 \%$ in virtual condition.

Across both situations (aligned and misaligned) no significant effect of the map conditions was found ( $p>.05)$ There was no significant effect of the same comparison for aligned situation only ( $p>.05)$ or for misaligned situation only ( $p>.05)$.

Our results reinforce the idea that a similar level of "accuracy" and consistency can be obtained when comparing the exploration of a virtual map with the exploration of a traditional tactile map.

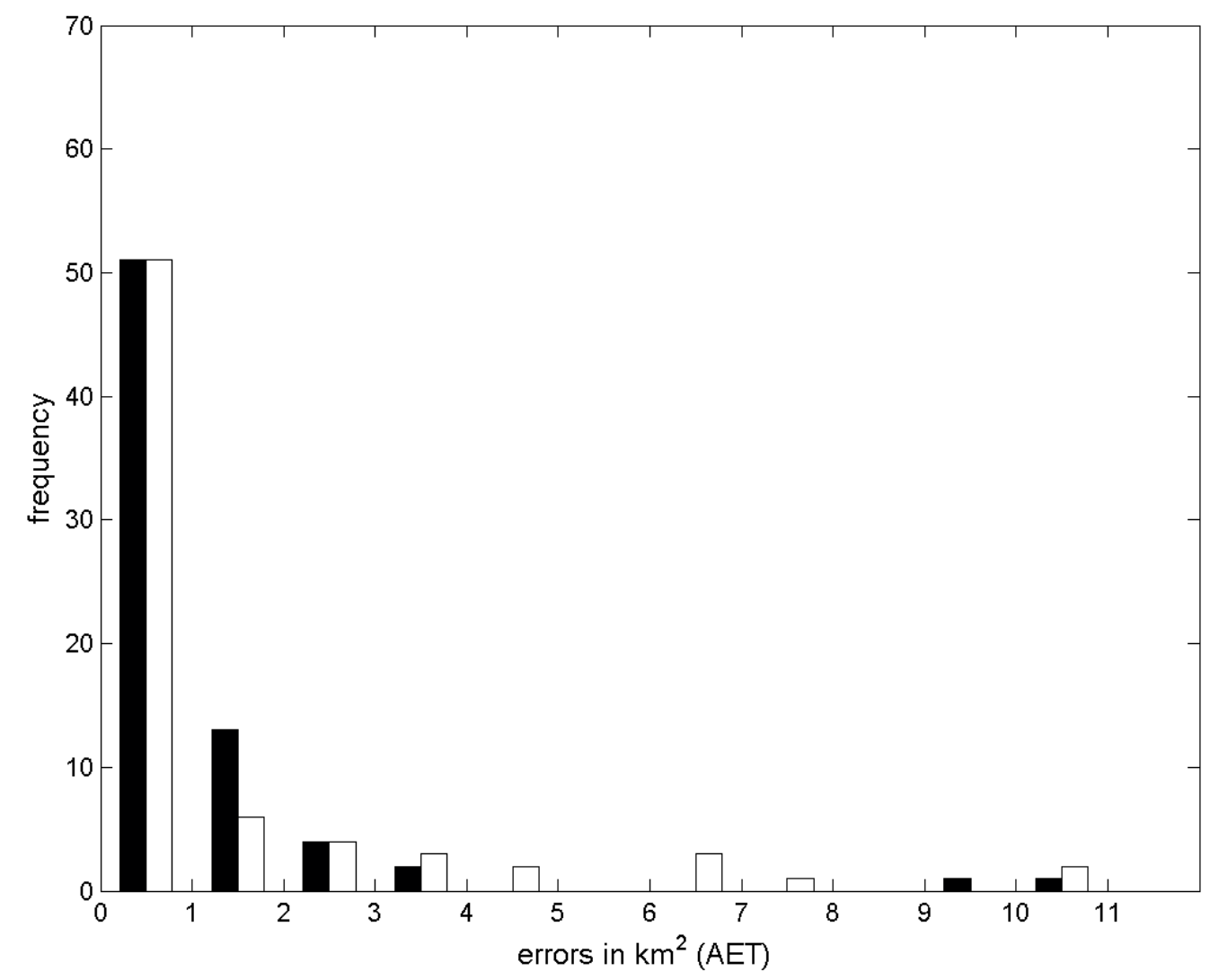

Figure 4: Frequencies of AET for tactile (Black bars) and virtual (white bars) conditions.

\section{Discussion}

In this preliminary experiment, the assessment of the consistency of the areas of the error triangles (AET) built by blind participants revealed a strong alignment effect in both the tactile and virtual condition. It appears that the coordination of ego- and allo- centric frames of reference remains a critical point. Importantly though, the results did not show any performance differences between the tactile map and the virtual environment in either the aligned or misaligned scenarios. Tactile maps did not perform better, but were equivalent to 
the virtual environment in the generation of cognitive maps. This held true for the generation of a mental representation, and for the integration of ego and allocentric frames of reference. This last result is surprising if we consider at least the two following reasons. Firstly, participants are much more familiar with tactile maps than virtual one. Secondly the force feed-back technology used in our experimental setting is not available for blind people in daily life. Intuitively a static tactile map accessed by one or more hands, would outperform a single point stylus in a virtual environment. The equivalence of the spatial performances produced after having explored the tactile map with two hands and the virtual map with only the stylus, also raises the following questions. Which specific encoding processes are involved in the construction of a non visual mental map by touch?

If one finger (an analogy to the stylus of the VR interface) is as efficient as conventional tactile map exploration strategies, which have the possibility for multiple scanning techniques and the use of more than one hand to provide an anchored frame of reference, then movement encoding appears to be particularly important in the virtual environment. Haptic (tactilekinesthetic) perceptions provided by the movements of one finger, as in our experiments, are necessarily sequential and tend to rely on the egocentric spatial frame of reference. So, we would expect them to be less powerful than the perceptions coming from multiple tactile map strategies potentially using two hands in order to build a cognitive map which should be able to integrate information in both ego- and allo- centric frames of reference. Millar (1994) and Gentaz and Gaunet (2006), propose that the use of a haptic modality to encode small scale space is mostly based on the memorization of the movement of kinesthetic information. Hatwell (2000) argued that the quality of mental spatial images is dependent upon the depth, exposure and detail of the encoding. In other words, the more participants grant attention to the task, the better their cognitive map is likely to be. This is the key of our results. A tactile map has a greater potential for accessing the configurational layout of the map scene and in our scenario the landmarks / beacons. This could lead participants to believe that they know where each beacon is and then do not explore further or to process more deeply spatial information. The movements induced by the sequential perceptions of one finger appear to encourage them to verify each element many times to ensure it is in the expected position. We suggest that the use of the Phantom haptic device forces participants to encode information more deeply in a virtual condition rather than in tactile one. This is confirmed when looking at the exploration times that can be considered as an indicator of the amount of cognitive resources devoted to the task. This process could lead participants to encode spatial invariants 
as common benchmark of current movement and generate a more durable spatial mental image. So, the constraints inherent in the virtual map initially viewed as a problem may in fact potentially turn out to be a more efficient manner to encode a small scale spatial layout regardless of the required exploration time.

Another difference exists between tactile and digital maps. The perimeter of the tactile map is readily tangible; it is a regular rectangle with discrete boundaries. Contrary to this the workspace of the Phantom haptic device is an ellipse generated by the physical constraints of the device (Figure 5). Participants are able to use the perimeter of the tactile map to encode the relationships between the perimeter, beacons and inherent spatial relationships to form a mental reference. As Hill and Rieser (1993) explained, the perimeter strategy allows blind people to refer to an external reference which creates a solid mental invariant. Here participants use it to recall the locations of some elements relative to the boundaries of the map before mentally repositioning the rest of the configuration. This is not possible in the virtual condition because of the lack of perimeter regularity. The perimeter does not feel like any well-known shape, that could form a psychological schemata and consequently the perimeter is hard to memorize. Participants did not make use of the perimeter in the virtual condition. If the perimeter provides participants with an external constant frame of reference in the tactile condition, it may be possible that gravity provides the same function in a vertical virtual environment. In addition as blind people are more familiar with tactile maps, the lack of significant difference between the precision of the cognitive maps encoded from tactile and virtual spaces could further support the important role of movement encoding to memorize space. It would be reasonable to expect that more in-depth training would allow blind people to benefit more widely from the movement encoding of space to build resilient, detailed cognitive representations of space, invariants that could coordinate more efficiently ego- and allo- centric spatial frame of reference. 

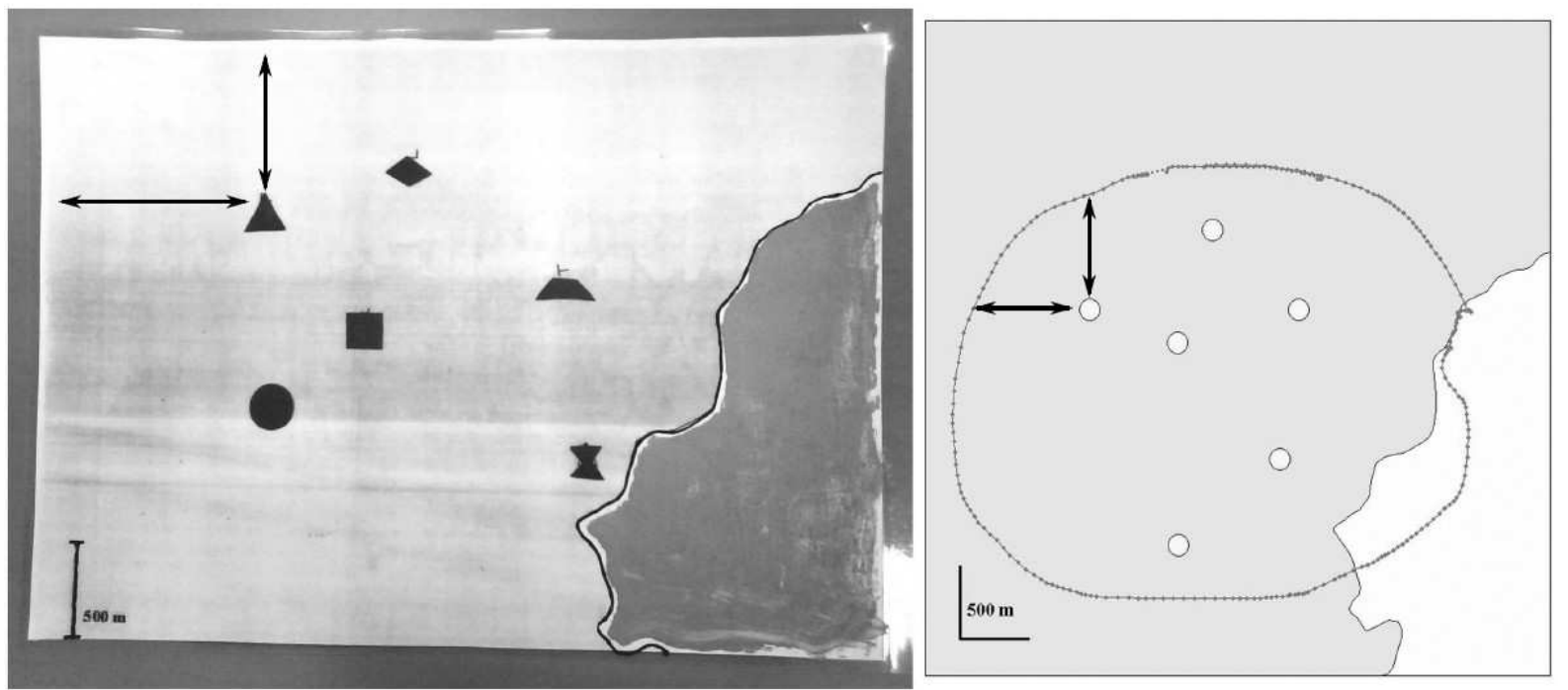

Figure 5: The perimeters of tactile and virtual maps. The first one is regular and easy to feel while the second one is irregular and not precisely defined.

The virtual SeaTouch map is in the vertical plane while tactile map is in the horizontal one. The vertical plane introduces the gravity invariant as a particular form of spatial reference. Pozzo et al. (1998) showed that gravity can be regarded as either initiating or braking arm movements and, consequently, may be represented in the motor command at the planning level. So, the perception of the verticality seems to be widely involved in the sensorimotor hand control and may be a major perceptible cue if available to encode a manipulatory space without vision. In line with this theory, different studies have previously demonstrated the resiliency of gravity perception (e.g. Gentaz and Hatwell, 1996; Senot et al., 2005). Thus, one could suggest that blind participants use the vertical axis as a tangible invariant to memorize the relationships between the positions of the beacons. This appears to facilitate the building of durable benchmarks into the configuration in a vertical virtual condition which could in part account for our findings.

However, our sample size was small. Future research with larger numbers of participants will investigate more precisely the influence of the movement encoding by controlling for perimeter and gravity effects. In addition we will focus on the exploration strategies to better understand the non visual encoding processes. These preliminary results show promise for the utility of virtual environments in representation spatial information to individuals without sight. 


\section{Acknowledgements}

We would like to express our gratitude to all those who gave us the possibility to complete this study. We want to thank the blind sailors of Orion association ${ }^{1}$ which accepted to perform experiments but also CECIAA ${ }^{2}$ society for funds and the master graduate students in computer science in the European Center for Virtual Reality ${ }^{3}$ for helping to the implementation of SeaTouch.

\section{References}

Espinosa, M., Ungar, S., Ochaïta, E., Blades, M., \& Spencer, C. (1998). Comparing methods for introducing blind and visually impaired people to unfamiliar urban environments. Journal of Environmental Psychology , 18, 277-287.

Gaunet, F., \& Thinus-Blanc, C. (1996). Early-blind subjects' spatial abilities in the locomotor space: exploratory strategies and reaction-to-change performance. Perception, 25, 967-981.

Gaunet, F., Martinez, J. L., \& Thinus-Blanc, C. (1997). Early-blind subjects' spatial representation of manipulatory space: exploratory strategies and reaction to change. Perception, 26, 345-366.

Gentaz, E., \& Gaunet, F. (2006). L'inférence haptique d'une localisation spatiale chez les adultes et les enfants : étude de l'effet du trajet et du délai dans une tâche de complètement de triangle. L'année psychologique , 106, 167-190.

Golledge, R.G. (1991). Tactual strip maps as navigational aids. Journal of Visual Impairment \& Blindness, 85, 296-301.

Golledge, R.G. (1993). Geography and the disabled: A survey with special reference to vision impaired and blind populations. Transactions of the Institute of British Geographers New Series, 18, 63-85.

Hardwick, D., McIntyre, C., \& Pick Jr, H. (1976). The Content and Manipulation of Cognitive Maps in Children and Adults. Monographs of the Society for Research in Child Development , 41, 1-55.

\footnotetext{
${ }^{1}$ http://orion-brest.com

${ }^{2}$ http://www.ceciaa.com

${ }^{3}$ http://www.cerv.fr
} 
Hatwell, Y.; Streri, A. \& Gentaz, E. (2003) Touching for knowing: cognitive psychology of haptic manual perception. John Benjamins Pub.

Hill, E. W., \& Rieser, J. J. (1993). How persons with visual impairments explore novel spaces: Strategies of good and poor performers. Journal of Visual Impairment and Blindness , 87, 8-15.

Hill, E., \& Ponder, P. (1976). Orientation and Mobility Techniques: A Guide for the Practitioner. New York: American Foundation for the Blind.

Jansson, G. \& Billberger, K. (1999) The PHANToM used without visual guidance. Proceedings of the First PHANToM Users Research Symposium, 1999.

Jansson, G. (2001) Perceiving complex virtual scenes with a PHANToM without visual guidance.Paper presented at the "Touch in Virtual Environments" Workshop, International Media Systems Center, University of Southern California, Los Angeles, CA.

Kitchin, R. M., \& Jacobson, R. D. (1997). Techniques to collect and analyse the cognitive map knwoledge of persons with visual imparment. Journal of visual impariment and blindness , 91 (4), 360-376.

Kitchin, R., Blades, M., \& Golledge, R. (1997). Understanding spatial concepts at the geographic scale without the use of vision. Progress in Human Geography, 21, 225-242.

Klatzky, R. (1998). Allocentric and egocentric spatial representations: Definitions, distinctions, and interconnections. In C. Freksa, C. Habel, \& K. F. Wender, Spatial cognition - An interdisciplinary approach to representation and processing of spatial knowledge (pp. 1-17). Berlin: Springer-Verlag.

Klatzky, R. (1999). Path completion after haptic exploration without vision: Implications for haptic spatial representations. Perception and Psychophysics , 61, 220--35.

Kosslyn, S., Pick, H. L., Jr., \& Fariello, G. (1974). Cognitive maps in children and men. Child Development, 45, 707-716.

Lahav, O., \& Mioduser, D. (2008). Haptic-feedback support for cognitive mapping of unknow spaces by people who are blind. International Journal of Human-Computer Studies , 66, 23-35.

Leonard, J., \& Newman, R. (1967). Spatial orientation in the blind. Nature , 215, 14131414. 
Loomis, J., Klatzky, R., Golledge, R., Cicinelli, J., Pellegrino, J., \& Fry, P. (1993). Nonvisual navigation by blind and sighted: Assessment of path integration ability. Journal of Experimental Psychology: General , 122, 73--91.

Millar, S. (1988). Models of Sensory Deprivation: The Nature/Nurture Dichotomy and Spatial Representation in the Blind. International Journal of Behavioral Development, $11,69-87$.

Millar, S. (1994). Understanding and Representing Space: Theory and Evidence from Studies with Blind and Sighted Children. Oxford: University Press.

Nemec, V.; Sporka, A. \& Slavik, P. (2004) Haptic and spatial audio based navigation of visually impaired users in virtual environment using low cost devices. Lecture notes in computer science, Springer, 452-459

Piaget, J., \& Inhelder, B. (1967). The child's conception of space. New York: Norton.

Pozzo, T., Papaxanthis, C., Stapley, P. \& Berthoz, A. (1998) The sensorimotor and cognitive integration of gravity. Brain Research Reviews, 28, 92-101

Revesz, G. (1950). Psychology and art of the blind. London: Longmans.

Rice, M.; Jacobson, R.; Golledge, R. \& Jones, D. (2005) Design Considerations for Haptic and Auditory Map Interfaces Cartography and Geographic Information Science, Cartography and Geographic Information Society, 32 (4), 381-391

Rossano, M. J., \& Warren, D. (1989). The importance of alignment in blind subject's use of tactual maps. Perception, 18, 805-816.

Rowell, J. \& Ungar, S. (2003) The world of touch: an international survey of tactile maps. Part 1: production. British Journal of Visual Impairment, 21, 98-104

Rowell, J. \& Ungar, S. (2003) The world of touch: an international survey of tactile maps. Part 2: design.British Journal of Visual Impairment, 21, 105-110.

Siegel, A., \& White, S. (1975). The development of spatial representations of large-scale environments. New York: Academic Press.

Spencer, C. \& Blades, M. (1986). How do people use maps to navigate through the world? Cartographica: The International Journal for Geographic Information and Geovisualization. 24(3), 64-75. 
Tatham, A. (2003) Tactile mapping: Yesterday, today and tomorrow. The Cartographic Journal, 40, 255-258.

Tellevik, J. M. (1992). Influence of Spatial Exploration Patterns on Cognitive Mapping by Blindfolded Sighted Persons. Journal of Visual Impairment and Blindness , 86, 221-224.

Thinus-Blanc, C. (1996). Animal Spatial Cognition: Behavioural and Brain Approach. London: World Scientific.

Tolman, E. (1948). Cognitive map in rats and men. Psychological Review, 189-209.

Tolman, E. (1948). Cognitive map in rats and men. Psychological Review , 189-209.

Ungar, S. (2000). Cognitive mapping without visual experience. In R. Kitchin, \& S. Freundschuh, Cognitive Mapping: Past, Present and Future (pp. 221-248). London: Routledge.

Ungar, S., Blades, M., \& Spencer, C. (1996). The ability of visually impaired children to locate themselves on a tactile map. Journal of Visual Impairment \& Blindness, 90, 526535.

Ungar, S., Blades, M., Spencer, C., \& Morsely, K. (1994). Can Visually Impaired Children Use Tactile Maps to Estimate Directions? Journal of Visual Impairment and Blindness , 88, 221--33.

Wickens, C. (1999). Frames of reference for navigation. In D. Gopher, \& A. Koriat, Attention and Performance XVII: Cognitive Regulation of Performance: Interaction of Theory and Application (pp. 113-142). Cambridge: MIT Press.

Wood, D. \& Fels, J. (1992) The power of maps. Guilford Publication. 